\title{
FACES DA CULTURA E DO JEITINHO BRASILEIRO: UMA ANÁLISE DOS FILMES O AUTO DA COMPADECIDA E SANEAMENTO BÁSICO
}

\author{
D. C. GOMES ${ }^{1 *}$, A. F. G. MORAES ${ }^{2}$ e D. H. HELAL ${ }^{3}$ \\ ${ }^{1}$ Instituto Federal do Rio Grande do Norte - Campus Currais Novos - Mestre em Administração \\ ${ }^{2}$ Universidade Federal de Minas Gerais - Doutoranda em Administração \\ ${ }^{3}$ Fundação Joaquim Nabuco e Universidade Federal da Paraíba - Doutor em Ciências Sociais \\ danilo.cortez@ifrn.edu.br*
}

Artigo submetido em abril/2015 e aceito em outubro/2015

DOI: $10.15628 /$ holos.2015.2988

\section{RESUMO}

A cultura brasileira, com suas diversas características, permite análises mais apuradas em relação às origens, influências e contexto. Nesse estudo, a semelhança e diversidade da cultura nacional se fundem, haja vista que se buscou observar as representações do jeitinho brasileiro a partir das análises dos filmes 0 Auto da Compadecida e Saneamento Básico. Autores clássicos sobre cultura brasileira como DaMatta (1986), Holanda (1995) e Freyre (2006) foram pesquisados, além de estudos sobre o jeitinho brasileiro, como Barbosa, Costa e Vieira (1982), Barbosa (1992), Motta e Alcadipani (1999), Massukado-Nakatani, Mussi e Pedroso (2009). A presente pesquisa é de caráter qualitativo e utilizou-se da técnica de observação indireta para analisar os filmes comentados. Através de uma metodologia reflexiva, as categorias de análise dos dados tiveram como base os "desdobramentos" do jeitinho sintetizados por Massukado-Nakatani, Musi e Pedroso (2009). Se o jeitinho é exclusivamente brasileiro ou uma característica universal, não se sabe ao certo, mas as análises apresentadas neste artigo evidenciam que o jeitinho é presença marcante na cultura brasileira, seja nos morros e favelas do Rio de Janeiro, no sertão nordestino ou em uma simples comunidade no sul do país.

PALAVRAS-CHAVE: cultura nacional, jeitinho brasileiro, corrupção.

\section{BRAZILIAN CULTURE AND JEITINHO: AN ANALYSIS OF MOVIES O AUTO DA COMPADECIDA AND SANEAMENTO BÁSICO}

\begin{abstract}
The Brazilian culture, with its diverse characteristics, allows us the most exquesite analyses relating to the origins, influences, and context. In this study, the similarities and diversity of the national culture merge themselves, given that we sought to observe the representations of the so called "jeitinho brasileiro" (the Brazilian way) in the analyses of the movies O Auto da Compadecida and Saneamento Básico. Classical authors on Brazilian culture such as DaMatta (1986), Holanda (1995), and Freyre (2006) were researched, as well as studies about the "jeitinho brasileiro" such as Barbosa, Costa, and Vieira (1982), Barbosa (1992), Motta and Alcadipani (1999), Massukado-Nakatani, Mussi, and
\end{abstract}

Pedroso (2009). The present research is of qualitative character and the technique of indirect observation was used to analyze the commented movies. By means of a reflexive methodology, the analysis categories of the data have had as basis the developments of the "jeitinho" synthesized by Massukado-Nakatani, Musi and Pedroso (2009). It is not known if the "jeitinho" is exclusively Brazilian or a universal characteristic, but the analyses presented in this article show that the "jeitinho" is strongly present in the Brazilian culture, be it in Rio de Janeiro's slums, in the northeast backwoods, or in a simple community in the south of country.

KEYWORDS: national culture; brazilian jeitinho, corruption. 


\section{INTRODUÇÃO}

O cotidiano do brasileiro é marcado por certos hábitos que, na maioria das vezes, passam despercebidos devido a naturalidade que adquirem. Exemplos destes hábitos são o famoso "furar" fila, adentrar em filas especiais (as destinadas a gestantes, idosos, pessoas com deficiência, etc.), tentar conseguir vantagens de forma mais rápida através da amizade com terceiros ou da concessão de bens materiais e/ou dinheiro para estes, utilizar o poder que se tem para, do mesmo modo, conseguir vantagens, etc. O termo utilizado para conceituar tais atitudes é "jeitinho brasileiro", o conhecido ato de "dar um jeito" em determinadas circunstâncias, estando fortemente impregnado na cultura nacional, de modo que já foi objeto de estudo de diversos autores, dentre eles Barbosa, Costa e Vieira (1982), Barbosa (1992), DaMatta (1997), Alcadipani e Motta (1999), Mussi, Massukado-Nakatani e Pedroso. (2009), entre outros.

Os estudos de Barbosa, Costa e Vieira (1982), por exemplo, traçava relações entre o jeitinho e o formalismo/burocracia, presente no país. Os autores buscaram relacionar estas duas características presentes na cultura nacional: o formalismo e jeitinho, colocando como questão a possibilidade de ser ter, em uma sociedade marcada pela burocracia, patrimonialismo e impessoalidade, relações frouxas, pessoais, ou seja, ter o "jeitinho" como base. Já Alcadipani e Motta (1999) estudaram o jeitinho a partir de um traçado histórico, explicando as origens da colonização do país e da formação da sociedade brasileira como influenciadores de determinadas características na cultura do país, dentre elas o paternalismo, a pessoalidade e o formalismo, as quais, para os autores, são fatores influenciadores do jeitinho, ideia que concorda com o que foi exposto por Barbosa, Costa e Vieira (1982).

DaMatta (1997) por sua vez, buscou analisar a cultura brasileira a partir de suas festividades, a exemplo do Carnaval, como mencionado no próprio título, abordando a partir disto, características desta cultura, dentre elas, o jeitinho. Barbosa (1992), orientanda de DaMatta, analisou o jeitinho sob perspectivas do "bom" e do "mau", ou seja, até que ponto ele é visto como algo positivo e a partir de quê, ele passa a ser visto com maus olhos pela sociedade, apresentando ainda o jeitinho brasileiro como característica universal e não como exclusividade tupiniquim. Além destes, temos ainda Mussi, Massukado e Nakatani (2009), fazendo considerações sobre o jeitinho a partir da revisão de estudos anteriores e abordando alguns "desdobramentos" que o jeitinho possui, os quais podem ser, seguindo a ideia de Barbosa (1992), bons ou maus.

Entretanto, em que consiste, de fato, o tal jeitinho? Jeitinho é malandragem? É quebrar regras? É a falta de educação da população? Está diretamente relacionado ao dinheiro? Estes são alguns dos questionamentos que levarão ao entendimento dessa característica tão peculiar da cultura nacional, a qual, inclusive, já foi apresentado internacionalmente, através da imagem do papagaio Zé Carioca, personagem criado pela Walt Disney, onde nos filmes "Alô, Amigos" e "Você já foi à Bahia?", ambos da década de 1940, apresentavam o jeito malandro de ser do brasileiro, sempre escapando dos problemas pelas vias mais fáceis.

Essa representação do jeitinho brasileiro, além dos filmes já citados, também esteve presente em obras mais recentes, tais como: Tropa de Elite 1 e 2 (2007 e 2010, respectivamente), O Auto da Compadecida (2000), Deus é Brasileiro (2003), Brasília 18\% (2006), Caixa Dois (2007) Saneamento Básico (2007), dentre outros, além de esquetes de humor (Suborno, do canal Porta 
dos Fundos, 2013), documentários e curta metragens (Um jeitinho brasileiro, de 1990). Percebese assim, que tal característica vem sendo abordada em obras ficcionais, como forma, muitas vezes, de satirizar e ao mesmo tempo mostrar a realidade do país.

A análise de filmes tem sido um recurso utilizado em diversas áreas, como forma de enxergar a realidade na ficção, e auxiliar na compreensão de diversos temas. Na área de Administração não tem sido diferente, pois pesquisadores em todo o país já se utilizam desse recurso. Exemplos disto são os estudos de Mendonça e Guimarães (2008), Mello, Marçal e Fonsêca (2009), Leite et al. (2010), Leite et al. (2012) e Rezende e Araújo (2012), Tavares et al. (2012) dentre outros, que buscaram, a partir de filmes, gerar discussões sobre certas temáticas, recurso esse que pode auxiliar no aprendizado de conceitos, levando os alunos/leitores a obterem reflexões e novos olhares sob os assuntos abordados na sala de aula.

Desse modo, diante da exposição da importância dos estudos sobre cultura brasileira e suas características, em especial o "jeitinho"; da verificação de diversos filmes que abordam o tema, e ainda, em virtude da constatação de análises fílmicas como uma forma atual de pesquisa na área de Administração, o que vem sendo feito por diversos pesquisadores no país, como já apresentado, o presente artigo justifica sua importância. Nesse sentido, tem-se como objetivo observar como o jeitinho brasileiro aparece e de que modo ele é representado, a partir da análise dos filmes $O$ Auto da Compadecida e Saneamento Básico, tendo como base os "desdobramentos" do jeitinho brasileiro, sintetizados por Massukado-Nakatani, Musi e Pedroso (2009). Os filmes apresentam perspectivas e estilos em contextos diferentes, contudo, é nesse cenário de diversidade do cinema nacional que pretendemos observar cultura brasileira.

Para isso, se faz necessário que explanemos, a priori, sobre a cultura nacional e a partir dela, adentrar em uma de suas características: o "jeitinho". Junto a esta característica, e para sua melhor compreensão, se apresentam outras, que também contribuíram na formação da cultura brasileira e estão presentes nas relações sociais deste país, a exemplo do patrimonialismo, a cordialidade, o paternalismo, etc. Entender essa tão diversificada cultura é necessário para que se entenda melhor suas características mais peculiares.

Assim, se busca, na primeira seção, discorrer sobre a pluralidade da cultura brasileira e suas influências, formação e especificidades, com destaque aos pontos essenciais para o entendimento dessa diversidade. Em seguida, se adentra na discussão sobre o jeitinho brasileiro. Como ele se originou? Como se pode defini-lo? Quais seus desdobramentos? Esses são alguns dos questionamentos que se busca responder durante a seção. Em um terceiro momento é apresentada a metodologia utilizada para a realização das devidas análises dos filmes, objetos de estudo. Prosseguindo, apresentam-se, os resultados dessas análises, a partir do que foi discutido anteriormente e buscando encontrar os desdobramentos do elemento em questão no trabalho. Finalmente, na quinta e última seção, são apresentadas as devidas conclusões.

\section{A(S) CULTURA(S) BRASILEIRA(S)}

Comentar algo sobre cultura é tarefa sempre instigante e por que não dizer desafiadora, especialmente quando parte-se do pressuposto da heterogeneidade e diversidade de uma organização, de determinado local geográfico ou então de uma nação, de um país. Assim, essa primeira parte deste artigo busca apresentar de forma breve alguns aspectos relacionados à 
cultura brasileira com suas diversas especificidades, tendo em vista que dificilmente têm-se condições de analisar pormenorizadamente as várias e complexas peculiaridades de uma terra cheia de contrastes (MOTTA, 1997).

As definições de cultura são diversas e moldadas conforme o olhar aguçado do pesquisador e observando as realidades estudadas, sejam elas sociedades específicas como tribos, nações, regiões ou organizações que possuem princípios norteadores que alicerçam o ser de determinada organização, influenciando direta e indireta o modo de agir daqueles que a integram. Nesse aspecto, estudos sobre cultura brasileira e nacional tem sido desenvolvidos ao longo do tempo na tentativa de melhor compreender características tão heterogêneas e particulares.

Na esfera organizacional, o estudo de Alcadipani e Crubellate (2003) evidencia as pesquisas realizadas sobre cultura organizacional brasileira no âmbito da administração no período de 1991 a 2000. Os resultados apontam uma homogeneidade na forma como o tema é abordado e as análises são realizadas, isto é, as pesquisas em sua grande maioria não levaram em consideração a pluralidade e heterogeneidade próprias de um país continental. Por outro lado, autores clássicos como DaMatta (1986), Holanda (1995) e Freyre (2006) enfatizam essa diversidade a partir da colonização portuguesa, que muito influenciou e influencia a maneira de pensar, de agir e de ser do brasileiro.

Para Alcadipani e Crubellate (2003) tomando por base Ribeiro (1995), o Brasil é um país fundamentalmente plural que teve fortes e decisivas influências dos escravos advindos do continente africano, além dos índios que aqui já estavam antes dos europeus. Estes últimos portugueses, espanhóis, franceses, holandeses, italianos, alemães - também contribuíram nessa formação heterogênea e exclusiva, bem como os árabes e japoneses. Assim, "este país é um caleidoscópio de povos e etnias" (ALCADIPANI e CRUBELLATE, 2003, p. 65). Desse modo, urge enfatizar que a cultura brasileira é formada de diversas características regionais bem diferentes umas das outras, sem contar os vários processos econômico-culturais que essas regiões passaram de formas distintas e em tempos diversos.

De acordo com Bosi (1992, p. 308) "estamos acostumados a falar em cultura brasileira, assim, no singular, como se existisse uma unidade prévia que aglutinasse todas as manifestações materiais e espirituais do povo brasileiro". Entretanto, essa ideia única e singular pode ser perigosa ao ponto de não serem observadas as particularidades dessas distintas regiões e localidades, que possuem seus costumes, povos, tradições e valores próprios, comungados por aqueles que ali residem ou foram formados naquela percepção específica daquele contexto cultural.

Tal crítica a essa visão uniforme é feita por Alcadipani e Crubellate (2003) aos célebres resultados da pesquisa de Hofstede (1984), que incluem o Brasil como um país que possui uma cultura com tendências para estabelecer relações de dependência com elevada distância de poder; alta aversão à incerteza; comportamento orientado em longo prazo; características coletivistas e típicas da feminilidade. Muzzio (2010) também evidencia essa incoerência relacionada a percepção uniforme da cultura nacional, pois esses resultados apresentados por Hofstede (1984) podem "conter resultados que não expressem a complexidade e a diversidade do país" (MUZZIO, 2010, p. 449). Essa afirmação apenas evidencia apenas evidencia a necessidade de uma visão mais ampla e heterogênea quando o assunto é cultura organizacional. O mesmo autor enfatiza a preocupação com estudos recentes que insistem em não observar a diversidade cultural regional: 
Do ponto de vista internacional, os estudos comparativos que trabalham com a perspectiva de adaptação cultural já apresentam um volume significativo de pesquisa que enfatizam as distinções entre regiões ou nações, porém, não analisam o contexto subnacional, assumem que as nações são sinônimos de cultura, ou seja, não levam em consideração a possibilidade que nestes países haja uma diversidade cultural regional. (MUZZIO, 2010, p. 449)

Nesse sentido, países "continentais" como o Brasil estão numa condição de "inexploração" quando o quesito é cultura regional, pois a cultura diversa encontrada no país permite análises de vários contextos e não uma análise linear, mas sem sombra de dúvida, multifacetada, pois "alguns autores defendem que os estudos organizacionais não podem partir do pressuposto que existe uma homogeneidade cultural apenas por ser um único país desconsiderando a possibilidade de culturas subnacionais" (MUZZIO, 2010, p. 449).

Numa perspectiva pós-moderna, Alcadipani e Crubellate (2003, p. 66) com base numa interessante pesquisa bibliográfica, entende que "a cultura depende do contexto momentâneo", fugindo de generalizações e estruturações impermeáveis, que em tese não observam os detalhes e as ambiguidades inerentes às culturas organizacionais. É interessante observar como há distinções entre culturas regionais num país como o Brasil, tal como apresentado por Rodrigues; Tude (2008) quando analisou as diferentes percepções existentes entre as culturas gaúcha e baiana durante o convívio entre estes num ambiente de trabalho. Nesse sentido, o olhar para a cultura brasileira não pode ser homogeneizador, mas um olhar atento às peculiaridades existentes nas regiões diversas.

O estudo recente de Muzzio (2010, 447), analisa "o contexto cultural brasileiro e a sua influência no universo organizacional a partir de uma perspectiva cultural regional que não se limite à visão funcionalista e avance por meio de conceitos contemporâneos como os fluxos culturais e os códigos culturais locais", isto é, os aspectos regionais devem ser considerados nos estudos de cultura organizacional, tendo em vista que essas variáveis culturais podem influenciar positivamente nos resultados das organizações, a começar das relações internas e externas da organização.

Assim, as diversas culturas regionais entrelaçam-se numa panaceia de intenções e interesses que tendem a moldar as práticas dos indivíduos, grupos e organizações, como bem explicita Muzzio (2010, p. 452):

Nessa ótica, não existe uma lógica de cultura única, como uma fotografia com sua natureza estática, mas sim como um intercâmbio de várias culturas, que se entrelaçam em ondas de fluxos, irradiados de muitos lugares que são simultaneamente origem e destino desses cursos, incluindo aí os lugares virtuais.

Isso não quer dizer que não haja uma cultura dominante que prevalece e dita as normas/regras a serem obedecidas ou internalizadas por todos os indivíduos. Motta $(1997$, p. 28) explica claramente que "cada tipo de cultura exerce um tipo próprio de controle de seus membros participantes". No caso do Brasil, com suas excentricidades e particularidades, faz-se necessário observar inclusive "como a história brasileira influencia a construção do imaginário social de seu povo" (MACHADO, 2008, p. 46). Essa observação torna-se relevante, pois assim como a cultura exerce um tipo de controle, as características culturais - como o jeitinho brasileiro - podem atuar como uma espécie de controle social (MOTTA e ALCADIPANI, 1999). 
Roberto DaMatta $(1986 ; 1997)$ apresenta essa cultura nacional através dos carnavais, dos malandros e heróis; do espaço da casa e da rua; e até mesmo por meio das comidas típicas dessa terra. Sérgio Buarque de Holanda em Raízes do Brasil analisa o processo de colonização e a perene influência dos povos do Velho Continente nesse Brasil multifacetado. Ademais, o autor não objetiva apenas resgatar o passado em si, mas entender o passado e suas raízes para interrogar o futuro cheio de desafios (CARDOSO, 2013). Gilberto Freyre em Casa-Grande \& Senzala identifica traços marcantes da colonização do Brasil ao passo que analisa a realidade com base nessas relações de outrora, evidenciando o quanto a cultura brasileira está à mercê de aspectos diversos daqueles que preliminarmente surgem das análises mais superficiais. No entanto, vale observar a sugestão de Holanda (1995, p. 40) sobre uma análise mais aprofundada sobre cultura: "a experiência e a tradição ensinam que toda cultura só absorve, assimila e elabora em geral os traços de outras culturas, quando estes encontram uma possibilidade de ajuste aos seus quadros de vida".

Segundo Motta (1986), a cultura nacional só se tornará mais compreensível através de uma interpretação mais abrangente que envolva as análises das posições econômicas, políticas e culturais já ocorridas no Brasil. Dessa forma, DaMatta (1986, p. 12) ao apresentar as condições mais propícias para uma investigação antropológica e sociológica tendo como objetivo identificar a construção de uma identidade social, afirma:

Descobrindo como as pessoas se posicionam e atualizam as "coisas" desta lista, você fará um "inventário" de identidades sociais e de sociedades. Isso the permitirá descobrir o estilo e o "jeito" de cada sistema. Ou, como se diz em linguagem antropológica, a cultura ou ideologia de cada sociedade. Porque, para mim, a palavra cultura exprime precisamente um estilo, um modo e um jeito, repito, de fazer coisas.

Nessa perspectiva, algumas características da cultura brasileira são mais evidenciadas que outras, tais como o formalismo, que é a diferença entre o que a lei versa e a conduta concreta, sem que tal diferença implique punição para o infrator da lei, sendo considerada a principal causa do jeitinho brasileiro (MOTTA e ALCADIPANI, 1999); o paternalismo enquanto traço cultural que articula a concentração de poder e o personalismo entre os indivíduos, manifestando-se principalmente no patriarcalismo, isto é, na influência das relações pessoais e de confiança nas nomeações de cargos (SOBRA e PECl, 2013); o patrimonialismo, "definido de forma simples e sintética como a confusão entre o que é público e o que é privado" (MARTINS, 1997, p. 171); o clientelismo, que "repousa num conjunto de redes personalistas que se estendem aos partidos políticos, burocracias e cliques" (NUNES, 2010, p. 53).

Destaca-se outra característica - o personalismo - que na concepção de Nunes (2010, p. 52) em sua Gramática política do Brasil, "é bem ilustrada pela instituição do jeitinho e pelo uso da autoridade pessoal, tão bem representada pela expressão 'você sabe com quem está falando?'” Para este autor, as "relações pessoais e hierárquicas são cruciais para tudo, desde obter um emprego até um pedido aprovado por um órgão público; desde encontrar uma empregada doméstica até fechar um contrato com o governo; desde licenciar o automóvel até obter assistência médica apropriada" (NUNES, 2010, p. 52). Assim, há uma evidência marcante do enaltecimento dos brasileiros pelo jeitinho como um mecanismo cotidiano para a regulação e controle das relações sociais e instituições formais (NUNES, 2010; MOTTA e ALCADIPANI, 1999). 
Essas características culturais específicas e não necessariamente exclusivas do Brasil, tornam a cultura nacional ambígua e heterogênea. Mas para Motta (1997, p. 33), essa "ambiguidade favorece os caminhos alternativos, que incluem a criatividade e a inovação, mas também a descoberta e o cultivo do 'padrinho', o apelo às relações sociais informais como forma de reasseguramento, o uso do 'jeitinho' que surge no plano da lei". Nessa terra de contrastes chamada Brasil, tornou-se característica marcante o denominado jeitinho brasileiro, e é sobre este que se pretende deter um pouco mais, haja vista suas nuances e especificidades.

\section{O “JEITINHO BRASILEIRO”}

A cultura brasileira é diversa, repleta de características bastante peculiares e que, em certa medida, são resultantes do processo de formação da sociedade no país. Algumas dessas características, como o patrimonialismo, o paternalismo, a cordialidade, etc. foram comentadas na seção anterior. Nesta, se busca focar em uma das particularidades da cultura brasileira, o "jeitinho", elemento que permeará a análise dos filmes objeto desse estudo.

Mas, afinal, o que é o jeitinho brasileiro? No início deste trabalho foram citadas situações em que o famoso "jeitinho" estava presente, sempre com caráter de resolução de problemas. Porém, de fato, como se caracteriza o "jeitinho"? Terá ele apenas caráter de resolução fácil? Recompensas materiais e financeiras estão inclusas nessa definição, ou se pode atribuir a esses, o nome de corrupção? Diante desses questionamentos, se busca, baseado na literatura existente sobre o assunto, compreender e apresentar uma definição do que seria o famoso jeitinho brasileiro, de modo que, a partir de tal entendimento, se possa analisar as situações apresentadas nos filmes analisados.

O jeitinho brasileiro tem origem, segundo Holanda (1995) e Massukado-Nakatani, Musi e Pedroso (2009), nas relações de poder que formaram a sociedade brasileira. No texto destes últimos, se apresenta um resumo de visões sobre o jeitinho brasileiro, com a definição de autores como Guerreiro Ramos (1993), Campos (1966) e Rosenn (1971), onde é possível perceber a concordância destes em relação as origens históricas do país e do jeitinho. Para eles, o jeitinho se estabelece a partir da formação da sociedade nacional, com influências portuguesas, indígenas, etc.

Mais especificamente, é a partir da expansão ultramarina, quando a lógica do trabalho é modificada em Portugal passando-se a buscar formais mais fáceis de ganhar dinheiro, que novos valores são gerados e passam a influenciar na colonização do Brasil, fazendo com que a administração pública brasileira fosse pautada em um sistema de privilégios. Este, por sua vez, convivendo também com um sistema burocrático, passou a encontrar na pessoalidade, uma forma de escapar de tal burocracia, conseguindo através das relações pessoais, burlar o sistema. Essa forma de lograr as leis estabelecidas, nada mais seria do que o "jeitinho". (BARBOSA, COSTA, VIEIRA (1982); MARTINS (1997); MASSUKADO-NAKATANI, MUSI, PEDROSO (1999)).

Em meio a essa discussão de suas origens, cabe a pergunta: o jeitinho é algo característico apenas do brasileiro ou é universal? Barbosa (1992) afirma que o jeitinho possui caráter universal, ou seja, está presente em todo o mundo, não sendo apenas característica exclusiva do Brasil. Contudo, por que tal característica é tão comumente atribuída (ou unicamente?) à cultura brasileira, através das imagens repassadas ao mundo por intermédios dos filmes, documentários, 
etc.? A respeito dessa discussão, Motta e Alcadipani (1999) defendem que o jeitinho é brasileiro, discordando das ideias de Barbosa, Costa e Oliveira (1982), em que os mesmos afirmaram, através de análises de entrevistas, que o "dar um jeitinho" também acontecia em outros países, porém de forma maior, não nas pequenas peculiaridades do dia-a-dia.

Mas, afinal, o que é o jeitinho? Algumas definições a seguir irão auxiliar na formação de um conceito que usaremos como base para as análises posteriores.

\begin{abstract}
"O jeitinho se caracteriza por ser um conceito intermediário entre o favor e a corrupção, apesar de poder pender para ambos os lados, dependendo da situação e dos atores envolvidos." (MASSUKADO-NAKATANI, MUSI, PEDROSO, 2009, p. 107).

"O jeitinho é o típico processo por meio do qual alguém atinge um dado objetivo a despeito de determinações contrárias (leis, ordens, regras etc.). Ele é usado para "driblar" determinações que, se fossem levadas em conta, impossibilitariam a realização da ação pretendida pela pessoa que o solicita, valorizando, assim, o pessoal em detrimento do universal" (MOTTA e ALCADIPANI, 1999, p. 6).
\end{abstract}

Através desses conceitos é possível perceber que o jeitinho se caracteriza pela prestação de um favor a alguém, o qual pode vir ou não, acompanhado de recompensas materiais. Esse favor, geralmente, é contrário ou busca ir contra as leis e favorece o indivíduo, mas não prejudica o coletivo. Na primeira definição é possível perceber um elemento interessante e que, por vezes, se confunde com o jeitinho: a corrupção. Até que ponto uma ação é tida como jeitinho e a partir de que, ela pode ser caracterizada como corrupção?

Para Motta e Alcadipani (1999, p. 9), "diferentemente da corrupção, a concessão do jeitinho não é incentivada por nenhum ganho monetário ou pecuniário: a pessoa que dá o jeitinho não recebe nenhum ganho material ao concedê-lo". Concordando com essa ideia, Vieira (2008, p. 49) afirma que esses dois elementos também se distinguem nesse ponto: ganho monetário. 0 autor cita que: "a grande maioria dos exemplos de corrupção envolve transações impessoais e monetárias, diferindo do jeitinho, que trata de transações pessoais e não monetárias". Com essa definição, aparece mais um elemento para caracterizar a diferenciação entre a corrupção e o jeitinho: a impessoalidade.

Entretanto, alguns autores, a exemplo de Massukado-Nakatani, Musi e Pedroso (2009), diferem dessa concepção de que não há ganho material. Para eles, o jeitinho brasileiro pode vir, sim, acompanhado de recompensas financeiras, mas não necessariamente sempre acontece desse modo. Citam que quando as recompensas passam a ser exorbitantes, o título de jeitinho não mais se aplica, sendo caracterizado, então, como corrupção.

Nesta tentativa de definir esse elemento, se faz necessário apresentar algumas de suas características. Uma delas é o modo educado, cordial, com o qual ele é pedido, posto em prática. Segundo Motta e Alcadipani (1999, p. 9), a humildade, simpatia e cordialidade são necessárias na hora de se conseguir o jeitinho: "Para consegui-lo, o pretendente deve ser simpático, humilde e mostrar como a aplicação da determinação seria injusta para o seu caso". Por outro lado, se tem o jeitinho como uma prática que habita entre o desonesto, a corrupção, e o favor, um modo de se virar, como já foi apresentado anteriormente. (DAMATTA, 1997; MASSUKADO-NAKATANI, MUSI e PEDROSO, 2009). 
Vale salientar, ainda, que o jeitinho, se estabelece, segundo alguns autores, em contextos burocráticos, outra das características da cultura nacional. Para Barbosa, Costa e Vieira (1982) o jeitinho brasileiro é uma forma de conseguir enfrentar todo o processo burocrático, formal, patrimonialista, que também está intrínseco em nossas raízes. Contudo, esses autores vão além e mostram, principalmente através das análises de DaMatta (1997), que o jeitinho está presente em toda a realidade social. Barbosa, Costa e Vieira (1982) e Motta e Alcadipani (1999) também afirmam essa ligação com as burocracias, ao formalismo, associando o jeitinho brasileiro a este segundo, contudo, ressaltando que ele não deixa de lado outros tipos de relações.

É, assim, que estes autores classificam o "jeitinho" como uma forma de poder, em especial ao que tange a relação indivíduo/pessoa, pois passa a fornecer as pessoas (no sentido colocado por DaMatta, 1997) aquilo que apenas através da burocracia seria difícil de se conseguir. Sendo assim, o jeitinho acaba aparecendo como uma forma de poder, o que pode ser relacionado a sua origem, como afirmou Holanda (1995).

Porém, ao contrário da burocracia, o jeitinho está ligado a simpatia de quem o pratica, a sua cordialidade, como já comentado. É desta maneira que o jeitinho se afasta da corrupção, pois busca relações humanas em seu desenrolar sem necessariamente, envolver dinheiro ou bens, procurando atingir seus objetivos a partir das relações com pessoas que irão se solidarizar, e que buscam meios de resolver a situação de quem pede o "jeito". Contudo, e seguindo a ideia de autores já comentados, isso não exclui favores em troca de dinheiro. Inclusive, esta é a vertente chamada "negativa" do jeitinho. (BARBOSA, COSTA, VIEIRA, 1982; MASSUKADO-NAKATANI, MUSI e PEDROSO, 2009).

Sobre essa vertente "negativa", se tem Massukado-Nakatani, Musi e Pedroso (2009) sintetizando, o que chamam de "desdobramentos" do jeitinho, de modo a auxiliar no entendimento de tal conceito. Os autores apresentam que essa espécie de desdobramento pode conter aspectos positivos ou negativos. Dentre esses desdobramentos, destacam como positivos a criatividade, as habilidades de persuasão e resolução de problemas, adaptabilidade, improviso, etc. e dentre os negativos, a inadequação a normas, possibilidades de ser corrompido ou corromper, uso do poder e alienação. Como dito, é importante perceber esses desdobramentos, para que se tenha melhor ideia do que é o jeitinho. A propósito, são eles que irão nos auxiliar nas análises posteriores.

Percebendo os diversos e complexos elementos que compõem o jeitinho brasileiro, é possível concluir a respeito deste, que o mesmo é uma espécie de resolução facilitada de problemas, uma forma de burlar as regras, a burocracia, o formalismo, características também presentes na cultura nacional, podendo ser realizado através de favores por parte de quem se solidariza com a situação, ou até mesmo através da troca de bens financeiros e/ou materiais, contudo, levando em consideração o grau dessas trocas, pois, se exorbitantes, podem ser chamadas de corrupção. Assim, imbuídos da ideia do que é o jeitinho brasileiro, de seus limites e suas origens, é possível identificar seus desdobramentos.

\section{PROCEDIMENTOS METODOLÓGICOS}

Tentar entender a realidade social, empresarial ou algo do tipo através do olhar mais atento de um filme é uma possibilidade interessante que tem aos poucos sido utilizados na academia, a 
exemplo dos estudos de Mendonça e Guimarães (2008), Mello, Marçal e Fonsêca (2009), Leite et al. (2010), Leite et al. (2012) e Rezende e Araújo (2012), como comentado anteriormente. Nessa perspectiva, este artigo se propõe a observar como o jeitinho brasileiro aparece e de que modo ele é representado nos filmes O Auto da Compadecida e Saneamento Básico, tendo em vista que "o filme preenche uma função na sociedade que o produz: testemunha o real, tenta agir nas representações e mentalidades, regula as tensões ou faz com que sejam esquecidas" (VANOYE e GOLIOT-LÉTÉ, 2012, p. 54-55).

A análise fílmica é complexa, porém bastante rica, pois segundo Leite et al. (2012):

“[...] a análise fílmica foi apontada por Leite e Leite (2007) como relevante, ao afirmarem que um filme comercial pode se transformar em instrumento de uma série de pesquisas. A utilização desse filme, nessa perspectiva de projeto, depende da teoria que o pesquisador esteja estudando, considerando-se que, em geral, tal filme é fruto da experiência de observação da vida cotidiana por seus idealizadores." (LEITE et al., 2012, p. 222)

Assim, com base na citação de Leite et al. (2012), podemos reafirmar que obras cinematográficas partem de determinadas realidades, de sua observação, até se tornarem arte, o que proporciona o casamento da literatura existente sobre o tema com aquilo que é mostrado nas telas de cinema. Os mesmos autores ainda complementam a importância da análise fílmica ao afirmarem que:

“[...] a linguagem cinematográfica proporciona ao observador a sensação de espaço de coparticipante daquilo que vê descrito no filme, de modo que se tornem possíveis, decodificação e codificação de variados símbolos, quer com os textos, com as imagens ou com os comportamentos observados nos personagens. (LEITE et al., 2012, p. 217)

Entretanto, será a análise fílmica tão simples como apresentam Vieira et al. (2012)? Vayone e Goliot-Lété (2008, p. 12) torna a questão mais complexa ao afirmar que "Analisar um filme não é mais vê-lo, é revê-lo e, mais ainda, examiná-lo tecnicamente. [...] desmontar um filme é, de fato, estender seu registro perceptivo e, com isso, se o filme for realmente rico, usufruí-lo melhor". Desse modo, buscamos apresentar os filmes em questão de forma mais rica, como diz Vayone e Goliot-Lété (2008), ressaltando, a partir deles, desdobramentos do jeitinho brasileiro no decorrer da trama.

Nesse sentido, a presente pesquisa se encaixa em um perfil qualitativo, utilizando-se da técnica da observação indireta, a qual, segundo Leite et al. (2012) proporciona ao pesquisador rever as cenas de um filme tantas vezes quantas forem necessárias, para que se possa ter maior inferência sobre ele, pois "não é possível conduzir, elaborar, uma análise de filme apenas com base nas primeiras impressões" (VANOYE e GOLIOT-LÉTÉ, 2012). A pesquisa inclui assim, uma metodologia reflexiva, aquela que requer uma interpretação cuidadosa com reflexão sobre o que foi visto (LEITE et al., 2010).

Entretanto, antes de iniciar as análises, se deve ter em mente alguns obstáculos que esse tipo de estudo expõe. Vanoye e Goliot-Lété (2008) apresentam algumas dessas dificuldades, e é válido que as ressaltemos como forma de melhor analisar nosso objeto de estudo. Primeiramente, o autor ressalta que análises de obras cinematográficas possuem dificuldades em relação a 
literatura, por não possuir a homogeneidade desta segunda, restando aos filmes, transpor apenas imagens e sons, elementos não possíveis de verificação. $O$ autor também destaca que dificuldades podem surgir em relação a pouca ou exagerada quantidade de vezes em que se examina um vídeo.

Desse modo, cientes de tais obstáculos e buscando seguir as dicas de Vayone e Goliot-Lété (2008), se buscou rever os filmes mais de uma vez, sob uma ótica fora do "espectador comum" como forma de não condicionar a análise ao erro. Nesse sentido, as análises percorrerão diversas cenas do filme para observar como o jeitinho brasileiro aparece e de que modo ele é representado, ao mesmo tempo em que o contexto apresentado no filme é evidenciado para uma interpretação mais abrangente e conforme a ideia exposta na trama.

A partir das considerações metodológicas aqui explicitadas e com base no referencial teórico apresentado, se buscou, inicialmente, definir as temáticas e as categorias utilizadas na análise. Assim, tais categorias para a análise dos dados emergiram do trabalho de MassukadoNakatani, Musi e Pedroso (2009), sendo elas: a persuasão, o improviso, a adaptabilidade, a criatividade, a cordialidade, a corrupção, a alienação, e o uso de poder, sendo este último representado pela ideia de DaMatta do "Sabe com quem está falando?". O Quadro 1 apresenta as categorias do jeitinho que serão trabalhadas.

Quadro 1 - Desdobramentos positivos e negativos do "jeitinho"

\begin{tabular}{|c|c|c|c|}
\hline $\begin{array}{l}\text { Número relativo a } \\
\text { característica }\end{array}$ & $\begin{array}{c}\text { Desdobramentos } \\
\text { positivos }\end{array}$ & $\begin{array}{l}\text { Número relativo } \\
\text { a característica }\end{array}$ & $\begin{array}{c}\text { Desdobramentos } \\
\text { negativos }\end{array}$ \\
\hline $\mathbf{1}$ & Criatividade e Inovação & 1 & $\begin{array}{c}\text { Tendência a } \\
\text { inadequação as } \\
\text { normas }\end{array}$ \\
\hline 2 & $\begin{array}{c}\text { Iniciativa para mudança } \\
\text { (de determinada situação) } \\
\text { e habilidade de resolução } \\
\text { de problemas }\end{array}$ & 2 & $\begin{array}{c}\text { Propensão a } \\
\text { corromper ou a ser } \\
\text { corrompido }\end{array}$ \\
\hline 3 & $\begin{array}{l}\text { Habilidade de persuasão e } \\
\text { conciliação (negociação) }\end{array}$ & 3 & $\begin{array}{c}\text { Tendência ao uso } \\
\text { de recurso de } \\
\text { poder }\end{array}$ \\
\hline 4 & $\begin{array}{l}\text { Adaptabilidade e } \\
\text { flexibilidade }\end{array}$ & 4 & $\begin{array}{l}\text { Alienação } \\
\text { (tendência a se } \\
\text { deixar ser } \\
\text { manipulado) }\end{array}$ \\
\hline 5 & $\begin{array}{l}\text { Habilidade no } \\
\text { relacionamento pessoal }\end{array}$ & - & - \\
\hline 6 & $\begin{array}{l}\text { Capacidade de } \\
\text { improvisação }\end{array}$ & - & - \\
\hline
\end{tabular}

Fonte: Massukado-Nakatani, Musi e Pedroso (2009)

A escolha dos filmes, por sua vez, se deu em virtude de pesquisas prévias acerca da questão do "jeitinho" no cinema nacional. Diversos foram os filmes assistidos até que se chegasse na escolha de dois, sendo eles: Saneamento Básico, de 2007, com direção de Jorge Furtado, que mesmo sem a repercussão que os demais apresentaram no cinema nacional, trata da temática do jeitinho de forma simples e cômica, porém totalmente atual. Outro filme analisado, e O Auto da Compadecida, produzido nos anos 2000 sob a direção de Guel Arraes e inspirado na obra de Ariano Suassuna, trata de aspectos mais corriqueiros da sociedade, mesmo em um contexto específico, o sertão nordestino. 
Logo após a definição dos critérios utilizados e da escolha dos filmes, os mesmos foram, mais uma vez, assistidos e feitas as devidas anotações. Uma segunda etapa de análise foi realizada de modo a melhor visualizar cenas, falas, gestos, etc., que passaram despercebidos na primeira análise. Assim, os filmes foram sendo revistos a medida que os pesquisadores julgaram necessários. Após as análises, foram montados quadros contendo as cenas (tempo aproximado em que a cena ocorreu, descrição da situação e classificação dentro dos desdobramentos do Quadro 1) que apresentavam, durante todo o filme, os exemplos mais representativos do que se buscou no trabalho. Isto feito, buscou-se produzir um quadro para cada filme e analisá-los separadamente, de modo que facilite o entendimento das análises. Para finalizar, reflexões de forma geral foram feitas a respeito dos filmes com base na literatura apresentada.

\section{ANÁLISE DOS FILMES}

A análise dos filmes, como já mencionado, será baseada nos elementos do Quadro 1 Desdobramentos positivos e negativos do "jeitinho". Assim, buscamos expor um pouco da temática do filme para então, partir as análises.

O próximo filme analisado trata-se de uma comédia renomada lançada no segundo semestre de 2000, sendo dirigida por Guel Arraes e roteiro de Adriana Falcão, que se basearam no romance de mesmo nome escrito pelo grande Ariano Suassuna. Os protagonistas João Grilo (Matheus Nachtergaele) e Chicó (Selton Mello) aprontam diversas travessuras num cenário nordestino e cheio de vivacidade quanto às características da cultura regional. No Quadro 2 encontram-se os desdobramentos do jeitinho brasileiro observados neste célebre filme do cinema nacional.

A forma cômica e romanceada do filme "O Auto da Compadecida" traz características fortes e marcantes do sertão nordestino, com evidências nas relações regionais de uma determinada época em que o coronelismo, a religiosidade, particularmente o catolicismo, e a cultura popular eram pilares da sociedade.

Nesse contexto, tomando por base os desdobramentos do jeitinho brasileiro apresentados por Massukado-Nakatani, Musi e Pedroso (2009), bem como as cenas descritas no Quadro 4, percebe-se que a capacidade de improvisação (6), a criatividade e inovação (1) e a iniciativa para mudança e habilidade de resolução de problemas (2) estão presentes enquanto desdobramentos positivos do jeitinho. Entretanto, a habilidade de persuasão e conciliação (3) também surge no filme.

Na verdade, a capacidade de improvisação de João Grilo - um hábil mentiroso - que mais tarde sofrerá (pelo menos por um instante) as consequências por suas mentiras, acompanha toda a estória do filme, a começar pela exibição do filme "Paixão de Cristo - o filme mais arretado do mundo" que não ocorre conforme planejado. Todavia, o jovem sertanejo sempre encontra uma forma de dá um jeitinho na situação, quando este é "usado para 'driblar' determinações que, se fosse levadas em conta, impossibilitariam a realização da ação pretendida pela pessoa que o solicita, valorizando, assim, o pessoal em detrimento do universal" (MOTTA e ALCADIPANI, 1999, p. 6).

As cenas em que João Grilo e Chicó buscam trabalho na Padaria, a malandragem daquele prevalece para reduzir sua jornada de trabalho, algo semelhante quando conseguem convencer o 
padre para abençoar a cachorra (que não era do Major Antônio Dias, o que não fora revelado, mas descoberto). Para DaMatta (1986, p. 64), "o malandro, portanto, seria um profissional do "jeitinho" e da arte de sobreviver nas situações mais difíceis". Assim, pode-se afirmar que João Grilo é um verdadeiro profissional do jeitinho brasileiro, pois consegue vender um gato que "dá" dinheiro, além de conseguir ressuscitar Chicó e concomitantemente criar condições para a morte do Rei do Cangaço - o Virgulino Ferreira Lampião.

Quadro 2 - Desdobramentos do jeitinho brasileiro no filme $O$ Auto da Compadecida

\begin{tabular}{|c|c|c|c|}
\hline $\begin{array}{c}\text { Tempo aproximado da } \\
\text { cena }\end{array}$ & Descrição da cena & $\begin{array}{c}\text { Desdobramentos } \\
\text { Positivos } \\
\end{array}$ & $\begin{array}{c}\text { Desdobramentos } \\
\text { Negativos } \\
\end{array}$ \\
\hline 03:00min & $\begin{array}{c}\text { Na exibição do filme } \\
\text { Paixão de Cristo "O filme } \\
\text { mais arretado do mundo", } \\
\text { um problema inesperado } \\
\text { com a máquina interrompe } \\
\text { a sessão. Mas João Grilo } \\
\text { encontra um jeitinho para } \\
\text { não decepcionar os } \\
\text { telespectadores, para } \\
\text { infelicidade do Padre } \\
\text { João. }\end{array}$ & 2 e 6 & 2 \\
\hline 7:00min & $\begin{array}{c}\text { João Grilo - um } \\
\text { trabalhador dito } \\
\text { “preguiçoso” dá um jeito } \\
\text { de reduzir sua jornada de } \\
\text { trabalho na padaria, } \\
\text { mesmo que as custas do } \\
\text { trabalho em dobro do } \\
\text { amigo Chicó }\end{array}$ & 1 e 3 & 1,2 \\
\hline 23:00min & $\begin{array}{c}\text { A benção da cachorra... } \\
\text { Mas sendo cachorra de } \\
\text { rico e mais do Major } \\
\text { Antônio Morais, o padre } \\
\text { abençoa. }\end{array}$ & 1,2 e 6 & 2 \\
\hline 56:00min & $\begin{array}{l}\text { O gato "banqueiro", } \\
\text { semelhante a galinha dos } \\
\text { ovos de ouro. }\end{array}$ & 1,3 e 6 & 2 \\
\hline $1: 57 h$ & $\begin{array}{c}\text { A “ressurreição” de Chicó } \\
\text { através da gaita de João } \\
\text { Grilo. Deram um jeito até } \\
\text { de matar o Rei do } \\
\text { Cangaço - Virgulino } \\
\text { Lampião. }\end{array}$ & $1,2,3$ e 6 & 2 \\
\hline $2: 02 h$ & Juízo Final & 3 & - \\
\hline $2: 34 h$ & $\begin{array}{c}\text { O contrato para o } \\
\text { casamento entre Chicó e } \\
\text { Rosinha: tirar o couro sem } \\
\text { sangue. }\end{array}$ & 6 & 1 e 2 \\
\hline
\end{tabular}

Fonte: Elaboração própria com base nos dados da pesquisa.

No tocante aos desdobramentos negativos, há uma predominância na propensão a corromper ou a ser corrompido (2), haja vista que na maioria das vezes a mentira e a desonestidade são as principais características protagonizadas pelos atores João Grilo e Chicó. Nesse aspecto, o jeitinho revela-se aliado à corrupção e a mentira, como forma de alcançar interesses próprios (DAMATTA, 1997; MASSUKADO-NAKATANI, MUSI e PEDROSO, 2009). 
Por fim, na longa cena do "Juízo Final", a habilidade de persuasão e conciliação (negociação) torna-se presente e exacerbadamente utilizada, ao ponto de "salvar" todos os envolvidos no filme, inclusive o mais mentiroso e causador de desencontros e confusões - João Grilo. Nesse trecho, o jeitinho brasileiro confunde-se com a intercessão de Nossa Senhora em prol dos desvalidos, isto é, para tudo tem jeito: "Mãe, se a senhora continuar interferindo desse jeito por todos, o inferno vai terminar virando uma repartição pública. Existe, mas não funciona".

A outra comédia analisada nesse estudo não teve tanta repercussão como os demais filmes apresentados, todavia, sob a direção de Jorge Furtado e com atores como Fernanda Torres, Wagner Moura, Camila Pitanga, Lázaro Ramos e Paulo José, o contexto da singela comunidade da Linha Cristal localizada na serra gaúcha transforma-se a partir de uma reivindicação de uma comissão para pleitear a construção de uma fossa para o tratamento do esgoto da localidade. Assim, a comissão juntamente com uma servidora da prefeitura responsável pela verba necessária encontra um "jeitinho" para que a obra se inicie. Se ela vai ser concluída é outra estória. O Quadro 3 revela algumas cenas em que torna-se perceptível o jeitinho brasileiro discutido neste estudo.

O roteiro do filme Saneamento Básico baseia-se na tentativa de produção de um filme amador em prol da construção de uma fossa para a comunidade local. Mas por que isso? Logo nas primeiras cenas, há uma reivindicação plausível da comunidade representada por um conselho sobre a construção de uma fossa que certamente resolveria o problema temporariamente de saneamento básico daqueles moradores. Nesse sentido, ao entrar em contato com a prefeitura, dois dos representantes do conselho descobrem que não há recurso para o tal empreendimento, mas há sim recurso para outra finalidade, que é a produção de um filme de ficção. Então a servidora juntamente com o casal deram um jeitinho de não devolver o dinheiro a Brasília.

Nesse sentido, o jeitinho encontrado se caracteriza como um instrumento para enfrentar a burocracia estatal, formal e patrimonialista existente, tal como abordada por Barbosa, Costa e Vieira (1982). No filme em questão, o jeitinho se revelou na produção de um filme de ficção amador por amadores, que como única opção, preferiram aceitar tal desafio a continuar nas condições precárias pela falta de saneamento básico. Entre o poder fazer e o não poder, preferiram o não ficar sem fazer nada e deram um jeitinho, como apregoado por Da Matta (1986, p. 63):

No Brasil, porém, entre o "pode" e o "não pode", encontramos um "jeito". Na forma clássica do "jeitinho", solicita-se precisamente isso: um jeitinho que possa conciliar todos os interesses, criando uma relação aceitável entre o solicitante, o funcionário-autoridade e a lei universal.

Dessa forma, enquanto o filme a ser produzido era de ficção, o jeitinho brasileiro encontrado não era ficção, mas uma característica muito arraigada na cultura brasileira (DAMATTA, 1986; HOLANDA, 1995; MASSUKADO-NAKATANI, MUSI e PEDROSO, 2009).

De acordo com os desdobramentos positivos e negativos do jeitinho elaborados por Massukado-Nakatani, Musi e Pedroso (2009) e conforme o Quadro 5, os desdobramentos positivos são poucos e ocorrem apenas em uma cena, na qual a criatividade e inovação aliada à capacidade de improvisação permite com que os resultados possam ser atingidos, mesmo que no final o resultado não seja o preliminarmente planejado, pois mesmo com o êxito da produção do filme de ficção denominado "O Monstro do fosso", a obra da fossa e a principal reivindicação apresentada durante a comédia, continua inacabada. 
Quadro 3 - Desdobramentos do jeitinho brasileiro em Saneamento Básico, 0 Filme

\begin{tabular}{|c|c|c|c|}
\hline $\begin{array}{c}\text { Tempo aproximado da } \\
\text { cena } \\
\end{array}$ & Descrição da cena & $\begin{array}{c}\text { Desdobramentos } \\
\text { Positivos } \\
\end{array}$ & $\begin{array}{c}\text { Desdobramentos } \\
\text { Negativos } \\
\end{array}$ \\
\hline 12:23min & $\begin{array}{l}\text { O casal protagonista conversa com a } \\
\text { servidora da prefeitura em busca de } \\
\text { verba para a construção da fossa. Mas } \\
\text { a verba que existe é para produção de } \\
\text { um filme. Deram um “jeitinho" de não } \\
\text { devolver o dinheiro a Brasília. }\end{array}$ & 2 e 6 & 1 e 2 \\
\hline 18:00min & $\begin{array}{c}\text { Em mais uma conversa com a } \\
\text { servidora da prefeitura, fica claro que } \\
\text { não se pode devolver dinheiro a } \\
\text { Brasília. }\end{array}$ & - & 1 e 2 \\
\hline 36:00min & $\begin{array}{c}\text { O projeto inicial prevê a utilização de } \\
200 \text { sacos de cimento, mas a servidora } \\
\text { da prefeitura quer usar apenas } 140 \\
\text { sacos. }\end{array}$ & - & 1 e 2 \\
\hline 39:00min & $\begin{array}{c}\text { O projeto do filme é filantrópico! } \\
\text { Agora há uma busca por recursos } \\
\text { privados - patrocínios - para uma } \\
\text { obra pública. }\end{array}$ & 1,3 e 5 & 1 e 2 \\
\hline 1:06h & $\begin{array}{c}\text { O discurso do prefeito no conhecido } \\
\text { fenômeno de propaganda } \\
\text { governamental. }\end{array}$ & - & $1,2,3$ e 4 \\
\hline $1: 45 h$ & $\begin{array}{l}\text { Após o sucesso do filme lançado - O } \\
\text { Monstro do Fosso - muitos turistas } \\
\text { visitam o local das filmagens. Assim, } \\
\text { será necessário construir uma ponte no } \\
\text { local, além de concluir a obra do } \\
\text { saneamento básico. Mas não há verba } \\
\text { para isso, apenas verba para merenda } \\
\text { escolar. E não pode utilizar? }\end{array}$ & - & 1 e 2 \\
\hline
\end{tabular}

Fonte: Elaboração própria com base nos dados da pesquisa.

Por outro lado, os desdobramentos negativos predominam, especialmente quando relacionados à tendência à inadequação a normas (1) e a propensão a corromper ou a ser corrompido (2), a começar pelo momento em que se pretende desviar o recurso existente no poder executivo local. Essas características também se evidenciam no momento do planejamento da obra de saneamento básico quando da utilização de menos matéria-prima (no caso o cimento) para a execução da fossa, sem contar com o discurso propagandístico e eleitoreiro do prefeito em 
determinado ponto do filme, ou seja, no início da obra - momento oportuno para a implantação de uma placa sinalizando a atuação da prefeitura, além da cobertura do evento pela mídia local.

Vale salientar que a produção do filme de fiç̧ão tinha um custo. E como conseguir recursos? Enaltecendo de forma maquiada o perfil filantrópico do filme em busca de patrocínios que pudessem possibilitar a execução do mesmo. Surge então certa confusão entre o que é público e o que é privado (MARTINS, 1997).

Finalmente, a obra da fossa - objetivo inicial - não foi concluída, entretanto, o sucesso do filme "O Monstro do fosso" foi tamanho que de forma inusitada a localidade em que foram feitas as filmagens, passou a ser visitada por turistas, mudando consideravelmente a rotina pacata daquela região. Desse modo, a trama termina de forma semelhante como começou, ou seja, tendo em vista o fluxo de turistas, sugere-se que a prefeitura providencie a construção de uma ponte. Mas infelizmente não há verba para construção da ponte, apenas para aquisição de merenda escolar. E então, por que não utilizar essa verba? Certamente dá-se um jeitinho brasileiro!

\section{CONCLUSÕES}

Durante todo o trabalho foi possível perceber como a cultura brasileira é diversa e como seus mais peculiares elementos estão presentes no dia-a-dia da população, dentre eles, o famoso "jeitinho". Esta característica, como pode ser visto no decorrer do artigo já foi estudada por diversos pesquisadores, a exemplo de Barbosa (1992), Barbosa, Costa e Vieira (1982), Massukado Nakatani, Musi e Pedroso (2009), dentre outros, assim como também esteve representada em filmes nacionais, a exemplo dos aqui analisados.

Assim, tendo em vista o quanto são importantes os estudos que se debruçam sobre a cultura nacional, a proposta desse trabalho se reafirma pelo envolvimento de elementos artísticos (filmes, no caso) com pesquisas em Administração. Foi possível enxergar peculiaridades da cultura através da análise de produções nacionais, corroborando, assim, com o debate na área, buscando trazer alternativas ao estudo da Administração, em especial no que diz respeito à absorção da cultura nacional nas organizações.

Pode-se perceber nos dois filmes analisados - $O$ auto da compadecida e Saneamento básico -, o roteiro cômico, divertido e por que não dizer sutil, quando relacionado à temática do jeitinho, aborda contextos regionais e culturais bem distintos (o sertão nordestino e a região sul). No entanto, há características bem semelhantes em ambos os filmes, como a capacidade de improvisação e a tendência à corrupção, mesmo que numa linha menos explícita daquela observada em filmes que evidenciam a temática da corrupção em instituições específicas, como os filmes Tropa de elite 1 e 2.

Enquanto a mentira e o jeito malandro evidenciado em $\mathrm{O}$ auto da compadecida davam condições para que os resultados fossem atingidos pelos protagonistas, em Saneamento básico, o jeitinho se deu através de um esforço conjunto, inclusive do desvio de verba por parte da prefeitura, em busca de solução para um problema específico da comunidade. Por mais que os contextos, o modus operandi e os objetivos sejam diferentes nos filmes em questão, o jeitinho brasileiro continua traço marcante nas análises realizadas. Dessa forma, sugere-se que estudos posteriores analisem com mais afinco a utilização de filmes, especificamente de comédias, que abordem o jeitinho brasileiro, pois as análises fílmicas retratam uma faceta da sociedade que 
muitas vezes não é observada pelos espectadores. Assim, a utilização dos filmes torna-se um instrumento didático interessante a ser utilizado para discussões e debates em vários ambientes, como por exemplo, a sala de aula. Será essa (os filmes cômicos) uma tentativa irônica e mais suavizada de tratar uma mazela nacional? Certamente é um assunto que permite várias análises e possibilidades.

Por fim, conclui-se que, mesmo entre a contínua discussão de o jeitinho ser uma característica exclusiva do brasileiro ou uma característica universal, as análises apresentadas neste artigo evidenciam que ele é presença marcante na cultura brasileira, seja no sertão nordestino, ou então numa simples comunidade no sul do país.

\section{REFERÊNCIAS BIBLIOGRÁFICAS}

1. ALCADIPANI, Rafael; CRUBELLATE, João Marcelo. Cultura Organizacional: Generalizações improváveis e conceituações imprecisas. Revista de Administração de Empresas, São Paulo, v. 43, n. 2, p. 64-77, 2003.

2. BARBOSA, Lázaro Oliveira; COSTA, Frederico Lustosa da; VIEIRA, Clóvis Abreu. O "jeitinho" brasileiro como um recurso de poder. Revista de Administração Pública, Rio de Janeiro, v. 16, n.2, pp. 5-31, abril-julho, 1982.

3. BARBOSA, L. O jeitinho brasileiro. Rio de Janeiro: Campus, 1992.

4. BOSI, Alfredo. Dialética da Colonização. São Paulo: Companhia das Letras, 1992.

5. CARDOSO, Fernando Henrique. Pensadores que inventaram o Brasil. São Paulo: Companhia das Letras, 2013.

6. DaMATTA, Roberto. O que faz o brasil, Brasil? Rio de Janeiro: Rocco, 1986.

7. Carnavais, Malandros e Heróis: para uma sociologia do dilema brasileiro. 6 ed. Rio de Janeiro: Rocco, 1997.

8. FONTES, Érica Rodrigues. Corpo Negro e Cultura Brasileira em cinco filmes nacionais: uma leitura de Cidade de Deus, Orfeu Negro, Orfeu, Madame Satã e Ônibus 174. OPSIS, v. 7, n. 8, p. 125-138, jan./jun. 2007.

9. FREYRE, Gilberto. Casa-grande \& senzala. 45 ed. Rio de Janeiro: Record, 2002.

10. HOFSTEDE, G. Culture's consequences: international diferences in work-related values. London: Sage Publications, 1984.

11. HOLANDA, S. B. de. Raízes do Brasil. São Paulo: Companhia das Letras, 1995.

12. LEITE, Nildes Pitombo; LEITE, Fábio Pitombo; NISHIMURA, Augusto Takerissa; CHEREZ, Rodrigo Leandro. Educação tutorial: revitalizando ensino-aprendizagem e pesquisa em administração. Revista de Administração FACES Journal, v. 9, n. 4, set./dez. 2010.

13. LEITE, Nildes Pitombo; AMARAL, Iraides Gonçalves do; FREITAS, Alessandra Demite Gonçalves de; ALVARENGA, Marcelo Aparecido. Projetos educacionais e estudos observacionais em análise fílmica: qual o status de produção no Brasil? Revista de Gestão e Projetos - GeP, São Paulo, v. 3, n. 3, p 215-250, set./dez. 2012.

14. MACHADO, M. N. da M. Cultura e Imaginário Organizacionais: Análise Psicológica de Algumas Imagens Típicas Brasileiras. Pesquisas e Práticas Psicossociais, 3 (1), São João del-Rei, Agosto, 
2008, pp. 44-50.

15. MARTINS, H. F. A ética do patrimonialismo e a modernização da administração pública brasileira. In: MOTTA, Fernando C. Prestes e CALDAS, Miguel P., (orgs), Cultura Organizacional e Cultura Brasileira, SP, Atlas, 1997.

16. MASSUKADO-NAKATANI, Márcia Shizue; MUSSI, Fabrício Maron; PEDROSO, José Pedro Penteado. A relação entre o jeitinho brasileiro e o perfil empreendedor: possíveis interfaces no contexto da atividade empreendedora no Brasil. RAM, v. 10, n. 4. São Paulo, Jul./Ago. 2009, pp. 100-130.

17. MENDONÇA, J. Ricardo C. de; GUIMARÃES, Flávia Peixoto. Do quadro aos "quadros": o uso de filmes como recurso didático no ensino da administração. CADERNOS EBAPE.BR, Número especial, ago. 2008.

18. MOTTA, F. P. Cultura e Organizações no Brasil. In: MOTTA, Fernando C. Prestes; CALDAS, Miguel P. (Orgs.). Cultura Organizacional e Cultura Brasileira, São Paulo: Atlas, 1997.

19. MOTTA, Fernando C. Prestes; ALCADIPANI, Rafael. Jeitinho Brasileiro, Controle Social e Competição. Revista de Administração de Empresas, São Paulo, v. 39, n. 1, p. 6-12, 1999.

20. MUZZIO, H. Cultura Organizacional na Perspectiva Cultural Regional Brasileira. Revista Brasileira de Gestão de Negócios, São Paulo, v. 12, n. 37, p. 447-463, 2010.

21. NUNES, Edson de Oliveira. A gramática política do Brasil: Clientelismo, corporativismo e insulamento burocrático. 4 ed. Rio de Janeiro: Garamond, 2010.

22. REZENDE, Júlio F. D.; ARAÚJO, M. A. D. Uso do filme Matrix para o ensino da Administração. Revista Holos, Natal, ano 28, v. 4, p. 216-225, 2012.

23. RIBEIRO, Darcy. O povo brasileiro: a formação e o sentido do Brasil. São Paulo: Companhia das Letras, 1995.

24. RODRIGUES, Grace; TUDE, J. M. Culturas Regionais no Brasil: um Estudo sobre as Percepções Mútuas de Gaúchos e Baianos no Ambiente de Trabalho. In: V ENEO - Encontro Nacional de Estudos Organizacionais, 2008, Belo Horizonte. Resumo dos Trabalhos do V Encontro de Estudos Organizacionais, 2008.

25. SOBRAL, Filipe; PECl, Alketa. Administração: teoria e prática no contexto brasileiro. 2 ed. São Paulo: Pearson Education do Brasil, 2013.

26. TAVARES, Caroline Aparecida Bueno; FERREIRA, Roberto Carlos; SILVA, Marco Antonio Batista da; LEITE, Nildes R. Pitombo. Sucesso Psicológico, Felicidade e Linguagem Fílmica em Administração. Administração de Empresas em Revista, Curitiba, v. 11, n. 12, p. 1-18, 2012.

27. VANOYE, Francis; GOLIOT-LÉTÉ, Anne. Ensaio sobre a análise fílmica. Trad: Marina Appenzeller. 5 ed. Campinas: Papirus, 2008.

28. VIEIRA, Fabiano Mourão. Cultura brasileira e corrupção. Revista da CGU, Brasília, ano III, n. 4, jul./ago., p. 46-62, 2008. 